\title{
FAST Matrix: depicting the time-related aspect of urban development
}

\author{
R. Barelkowski \\ West-Pomeranian University of Technology in Szczecin, Poland
}

\begin{abstract}
The paper discusses the development of FAST Matrix within Fast Simulation Tool. Matrix is intended to combine and reproduce complex relations between the factors responsible for the efficiency of urban development. Currently apartment and housing areas have been introduced to the Matrix, and the work defines the structure of this mechanism, the taxonomy of sets of criteria and selected criteria in particular, and time-related mechanisms. The paper discusses risks and prospects of the Matrix, as well as its implementation in further planning tasks. Keywords: spatial planning, sustainability, FAst Simulation Tool, multicriteria matrix.
\end{abstract}

\section{Introduction}

Spatial planning requires a synergistic insight into complex conditions, factors, and agents which contribute to the real status of urban areas combined with the ability to predict the consequences of current state tendencies and decisions, and at the same time to allow for development and accommodation of the transformations to come. Planning is focused on the future, attempting to anticipate interconnected tendencies and patterns, both social and cultural. It is looking towards the near future, conceivable, definable. Grasping the process of time-related changes of urban environment in a reliable manner calls for an individual approach every time, while every city or every town has its own specific profile, manifests itself as a unique system, unprecedented and distinct to the extreme - culturally, physiographically, socially, economically and in many other ways.

The planners are therefore encouraged to employ variety of supporting tools, helping in the process to understand, analyze, and predict how initial urban or 
transformed patterns may evolve. True prediction can never be acquired, but the predominant trends and influencing factors can narrow down the available scenarios. These scenarios may provide useful and significant input to achieve efficient management, planning, development of structures, and in particular sustainable development.

Both simple and complex prognostics to analyze and understand variety of development scenarios, to consider flexible approaches to the problem of urban growth, are currently employed worldwide $[1,2]$. The prognostic tools must incorporate the second fundamental component, crucial for successful planning practice which is exemplified by integrated impact assessment - preceding the consequences of real-case considerations, with direct pressure of developing enterprises.

In this paper an important element of FAst Simulation Tool (FAST) system is presented - the one responsible for simulation formulas, processing the timerelated aspect of urban development. FAST Matrix builds multi-trigger reference for the simulation and provides the core prognostic mechanism for the majority of FAST modules. First, short introduction of the system is delivered. The intention to discuss the role of the matrix and its structure, acknowledging the taxonomy of a multitude of features, stimuli, and data is brought forward, then. It is also indispensable to point out the formulas defining the prognostic algorithms. Finally, the paper considers difficulties, risks, and imperfections pointing towards necessary future error corrections, improvements, and extensions of the matrix as well as the system itself, and at the same time perspectives of its further use.

\section{Attempting to decrypt complexity: FAST Matrix}

In 2014 a research team was established in order to elaborate the application with the main goal to deliver simple tool to support low level development decisions, mainly on basic level of local governments. The simulation of the development of urban structures has been designed as open structure giving the opportunity to start with selected, most expected modules - in described case housing area analytic tools and renewable energy site assessing tools, and then subsequently to deliver next modules - for industrial areas, service areas, and others. The concept is intended to serve not only qualified planners and urban designers, but most of all decision makers, which in Poland means most often local authorities [3].

FAST focuses on morphology of urban structures, and its development in timespace dependent on specific environment features found in particular place and correlated - in regards of spatial properties of researched area - in a matrix comprising over 100 various factors. It uses prognostics based on multi-criteria assessment of the initial status of the area, considers the adjacent and more distant, yet influential components of built and natural environment, supporting or compromising harmonious development. It emphasizes not only the areas and their content (inhabitants, functions, infrastructural systems), but it simulates (in a simplified manner) interrelations between elements of urban structure as well as urban processes. 
The research has been constructed with variety of supporting methods reinforcing the main concept of FAST system elaboration based on heuristics [4]. The supporting methods, e.g. methods of observation, classification methods, statistical methods, served the purpose of independent extraction of crucial data and error elimination in comparative procedures, with multiple verification of observable results as referential for the establishment of test algorithms.

The environment, both natural and built (civilization related) is a complex construct, evolving in a specific manner in which while several evolution patters can be easily discerned, it is not possible to impose any kind of standard causal connection between static initial configuration of the environment and its status being the result of impact of multiple factors of unique composition [5]. This level of complexity, found also in other systems or relations, has led Kay et al. [6] at the turn of the century to address the issue and propose an alternative approach based on dynamic fluctuations of those systems - classifying them as holarchic systems. Originally developed for social or ecological self-organized systems, Self-Organizing Holarchic Open (SOHO) developed Arthur Koestler's notion of holon into an extended and convincing description of blurred fluctuating hierarchy of various environmental components and determined behavior, in which no role is attributed permanently and the systemic patterns are able to shift seemingly unpredictably [7].

Justifiably dos Santos [8] points out that in planning a significant shift has taken place changing the practice of undertaking the attempts to determine the future into the process of considering the possibilities of the evolution of the system. However FAST attempts to go beyond proposed narratives, e.g. descriptive parallel scenarios, providing direct visual representation of a process. What is distinguishing for the system is its time-related approach to the problem of development of urban structures, as described by Janusz and Wardeski [9]. The time issue manifests itself in many aspects of spatial development. It refers to the rate of physical development, or how fast certain area can grow, densify, or transform in any other expected way. It corresponds to time-related infrastructural network expansion or transportation systems extensions. It can be found also in socio-economic, programmatic and organizational patterns strongly influencing the outcome of urban processes.

FAST Matrix is the vehicle to negotiate the individual configuration of the area under research, establishing its specific holarchic structure. Spatial focus of the tool substantiates sets of criteria and the concept of simplicity validates the elimination of considerations on details of more complex social composition. The structure of the Matrix is organized in two blocks - the first determines five sets of spatial criteria, and the second depicts the site related organization of development process. Spatial aspect of the development makes infrastructure and media a crucial set of ten criteria dependent on the rate of saturation, generating the K1 factor. Fourteen diverse criteria are dedicated to reflect the potential of transportation systems and road network, the K2 factor. There are twenty one aspects of typology of urban structure. Typology is strictly connected to function anchored in particular area, thus housing areas will be defined by detached housing, semi-detached or row housing, dense mixed housing, multi-apartment 
buildings and more. Generic factor for this set is K3. Matrix contains area related criteria - an extended set of thirty, totally contributing to generic K4 factor. Zone characteristics, access to attractive components of urban environment, the vicinity of oppressive components of the city (e.g. railway, heavy industry), the interpretive mechanism for CORINE Land Cover classification [10, 11], and demographic statistics are included in this group. The fifth set of factors is timerelated - it reflects the saturation of examined area with various objects, institutions, investments. Programmatic contents, like e.g. sports facilities, education facilities, access to health care, instead of scenario based on deterministic assumptions, mix wide range of information allowing to generate the resultant triggers jointly responsible (with other criteria) for the ultimate rate of the development of housing areas. The largest set containing thirty six various factors complete 111 modifiers of the first block of the Matrix, and this last set has generic timeline factors of K5.n, where $\mathrm{n}$ corresponds to the timespan, a division of total time under examination. Joint factor has been assumed as $F_{u}$.

The practice of spatial planning is always bound with the time span of the analysis. While short term predictions on a small scale are usually accurate, long term simulations or large area characteristics made the effort of establishing the valid scenario much harder, if possible at all. Practical time scale implemented in FAST Matrix is limited to 15 years including feasible, and economically efficient perspective of urban development of the area. The establishing of relationships between various sets of criteria with the acknowledgement of the timeline required the observation of multiple cases, analyzing of many various environments in order to understand the patterns of urban evolution. These observations were conducted currently in the area of Poznan, on the group of 22 diverse development areas. Particular interest was put on the examples of suburban areas, so typical to liminal municipal territories, both as an expression of studying urban sprawl in Poland and understand specificity of Polish land use as well as conditions shaping land use transformation. While FAST allows to diagnose basic interactions between the areas, including significant objects included in the Matrix, it was manageable to simultaneously visualize selected impacts, effects imposed on suburbs [12].

In the course of the research more complex model of the development of urban structures appeared to be necessary. The working formulas have to be established as continuous, while iterative components were responsible for the instability of the model.

Referential time $T_{r}$ has been set to 15 years. Time flow was set to be measured after every five years of the development and this periodic approach was also implemented in several time-related criteria:

- for 0 years Matrix generates K5.0 factor,

- for +5 years Matrix generates temporal development factor $\mathrm{F}_{\mathrm{t}}\left(\mathrm{d}_{1}\right)$, where " 1 " stands for 5 year timespan,

- for +10 years Matrix generates temporal development factor $\mathrm{F}_{\mathfrak{t}}\left(\mathrm{d}_{2}\right)$, where " 2 " stands for 10 year timespan,

- for +15 years Matrix generates temporal development factor $F_{t}\left(d_{3}\right)$, where " 3 " stands for 15 year timespan. 
The initial moment is determined by the formula:

$$
\mathrm{F}_{\mathrm{t}}\left(\mathrm{d}_{0}\right)=\mathrm{K} 1 * \mathrm{~K} 2 / \mathrm{K} 5.0
$$

The moments " +5 ", " +10 ", and " +15 " yrs are determined by formulas:

$$
\begin{aligned}
\mathrm{F}_{\mathrm{t}}\left(\mathrm{d}_{1}\right) & =\Delta \mathrm{t}\left(\mathrm{x}_{1}\right) * \mathrm{~K} 5.1 \\
\mathrm{~F}_{\mathrm{t}}\left(\mathrm{d}_{2}\right) & =\Delta \mathrm{t}\left(\mathrm{x}_{2}\right) * \mathrm{~K} 5.2 \\
\mathrm{~F}_{\mathrm{t}}\left(\mathrm{d}_{3}\right) & =\Delta \mathrm{t}\left(\mathrm{x}_{3}\right) * \mathrm{~K} 5.3
\end{aligned}
$$

Team assumed that the specific nature of investigated problem encourages the implementation of heuristics. It was not possible to establish clear, unequivocal causal relations for the majority of factors, this problem being intensified when relationships between factors have been discussed within the team. The search for an appropriate formula

The ratio of subsequent intervals depicting the dynamics of the urban development is derived from the above constituent strings. The first 5 years are determined by the formula (5), but the remaining two five year intervals are described by the formulas establishing ration between the first and the second period to be considered, respectively:

$$
\begin{gathered}
\mathrm{R}_{0>5}=(\mathrm{K} 1 * \mathrm{~K} 2 / \mathrm{K} 5.0) / \mathrm{F}_{\mathrm{t}}\left(\mathrm{d}_{1}\right) \\
\mathrm{R}_{5>10}=\mathrm{F}_{\mathrm{t}}\left(\mathrm{d}_{1}\right) / \mathrm{F}_{\mathrm{t}}\left(\mathrm{d}_{2}\right) \\
\mathrm{R}_{10>15}=\mathrm{F}_{\mathrm{t}}\left(\mathrm{d}_{2}\right) / \mathrm{F}_{\mathrm{t}}\left(\mathrm{d}_{3}\right)
\end{gathered}
$$

thus the dynamics can be calculated as ratios between the intervals:

$$
\begin{gathered}
\mathrm{D}_{\text {asc }}=\left[(\mathrm{K} 1 * \mathrm{~K} 2 / \mathrm{K} 5.0) / \mathrm{F}_{\mathrm{t}}\left(\mathrm{d}_{1}\right)\right] /\left[\mathrm{F}_{\mathrm{t}}\left(\mathrm{d}_{1}\right) / \mathrm{F}_{\mathrm{t}}\left(\mathrm{d}_{2}\right)\right] \\
D_{\text {des }}=\left[\mathrm{F}_{\mathrm{t}}\left(\mathrm{d}_{1}\right) / \mathrm{F}_{\mathrm{t}}\left(\mathrm{d}_{2}\right)\right] /\left[\mathrm{F}_{\mathrm{t}}\left(\mathrm{d}_{2}\right) / \mathrm{F}_{\mathrm{t}}\left(\mathrm{d}_{3}\right)\right]
\end{gathered}
$$

The coefficient generated by the first block of the Matrix is thus presented as the ratio connecting the dynamics of the development in its ascendancy (the first to the intermediary period) to the dynamics of the development in its descendant phase (the intermediary to the final period considered). Urban time-related development therefore may be written down as:

$$
\begin{gathered}
\mathrm{U}_{\mathrm{trd}}=\left\{\left[(\mathrm{K} 1 * \mathrm{~K} 2 / \mathrm{K} 5.0) / \mathrm{F}_{\mathrm{t}}\left(\mathrm{d}_{1}\right)\right] /\left[\mathrm{F}_{\mathrm{t}}\left(\mathrm{d}_{1}\right) / \mathrm{F}_{\mathrm{t}}\left(\mathrm{d}_{2}\right)\right]\right. \\
\left.=\left[\mathrm{F}_{\mathrm{t}}\left(\mathrm{d}_{1}\right) / \mathrm{F}_{\mathrm{t}}\left(\mathrm{d}_{2}\right)\right] /\left[\mathrm{F}_{\mathrm{t}}\left(\mathrm{d}_{2}\right) / \mathrm{F}_{\mathrm{t}}\left(\mathrm{d}_{3}\right)\right]\right\} * 1 / \mathrm{F}_{\mathrm{u}}
\end{gathered}
$$

Thorough analysis of examples from Poznan, Murowana Goslina, Oborniki, Rokietnica, Skoki, and Kobylniki, selected for the research proved the importance of the acknowledgement of the second block of information. Three sets of data have been connected by the formula: size of the area, organization of the development (organization type, e.g. general contractor or turnkey development), and number of active players (participants of the developmental effort). The relationship between those three elements has been ascribed as rational function:

$$
\mathrm{F}_{\mathrm{x}}=-\mathrm{A} /\left[\left(\mathrm{x} / 2^{\mathrm{B}}\right)+\mathrm{C}\right]
$$


where "A" corresponds to area size, "B" to the type of organization of development within the interval $[3,5]$, and " $\mathrm{C}$ " to the active cooperating parties sharing their efforts in order to acquire the hypothetical total saturation of the area (with arbitrarily scale set accordingly to the number of participants). For the above, if the value of " $x$ " is root, it means that the area has been completely filled, and that the development has been totally completed (which often is unachievable due to specific constraints):

$$
\mathrm{F}_{\mathrm{x}}=0 \Rightarrow \mathrm{C}_{\mathrm{S}}=1.0(100 \%)
$$

While the team was preliminarily searching for less complicated formula to decipher the connections and relations between the multiple factors affecting the development, the observations of particular cases led to establishing the above mentioned mechanisms as a basis for the Matrix, and corresponded to observable phenomena in multiple sites, receiving max deviation of $13.70 \%\left(\mathrm{C}_{\mathrm{S}}-\right.$ coefficient of saturation of an area).

\section{Risks and prospects}

FAST Matrix is a promising element of the FAST application. Current calibration of the Matrix has been accurate enough, considering the area of Poznan cases, that it was implemented to support decision-making process related to development of multi-apartment complex in Kowanowko, as well as remote location of multiapartment complex in Rutki near Oborniki and remote detached housing estate in Osowo. It is also used in larger development area of Wolne Tory Poznan redevelopment, the transformation process of old railway sidetracks, unused and decapitalized nowadays. While the research on the application and the Matrix is still in progress and its shape is rough, simultaneous alternative analyses have been performed leading to similar results. Maximum deviation of Matrix algorithms from independently imposed verification methods, which included the analyses of statistics, as well as queries, has not exceeded $12 \%$.

As said above, the tool seems promising, but it is important to underline that it has significant limitations and it proves usable under certain constraints. First of all, FAST Matrix results cannot be interpreted as data describing final, solid state of real development. Its role is purely supportive, explaining various dependencies, intertwined impacts, diverse factors have in distinct environments and area settings. FAST, and FAST Matrix in particular, depict raw approximation of possible developmental scenario. It diagnoses potential spatial problems, it returns population, media, infrastructural data related to development and status in time, but obviously it does not replicate reality, and most certainly still contains elements awaiting significant improvement.

Remaining a simplification, the model generated by FAST combines way too many factors to make the process of adjustment of the Matrix easy. What's more, this fundamental risk of invalid calibration is the main source of potential mishandling of the tool. It is important to notice, that adjustment cannot efficiently isolate singular factors in order to establish e.g. one sure factor, that can be eliminated in next calibration - another site will change its impact on how the case 
evolves and it will make it almost impossible to atomize the structure of the Matrix in order to receive better results.

Instead, the risk is controlled, but omitted - heuristics allow for holistic approach to the problem, and skip the issue of unequivocal determination of particular components, factors, triggers, focusing on the performance of the whole system. If the system works similarly and returns results imitating real cases, than small errors can be assumed as insignificant (if the scale of errors do not exceed stipulated rates).

The work on FAST is still developing and new modules are being elaborated (industrial, infrastructural - e.g. for renewable energy developments, already described and published [13]). Current Matrix was tested in decision-making support for highly autonomous real estates, built from scratch or with little existing urban substance in situ. This was the primary goal of the application - to help local communities and local authorities to understand the consequences of newly introduced housing areas, spilling outside the agglomeration limits. But according to the aims of the research both blending and reconfiguration strategies have to be supported, too [3]. This is the new perspective to process the verification in those remaining fields and extend the usefulness of the Matrix from newly established estates to all types of housing quarters. The FAST application as well as its constituent elements serve the purpose of integrating multiple determinants that drive the fluctuations of urban structures [14]. The understanding of the city and its related estates must be considered as a smart combination of observation skills, unique, adjustable approaches to every particular case, and tools enabling the testing of variety of development scenarios - repetitive modelling of possible evolutions will then allow to select an appropriate strategy for sustainable cities of the future.

\section{References}

[1] Magdi, S. A.: 2012, An urban growth model for strategic urban planning on a regional level: a proposed model prototype for Greater Cairo in the year 2050, in M. Pacetti, G. Passerini, C. A. Brebbia, G. Latini (eds.), The Sustainable City VII. Urban Regeneration and Sustainability, Wessex Institute of Technology, WIT Press, Southampton \& Boston, pp. 71-83.

[2] Laprise, M., Lufkin, S. and Rey, E.: 2014, The strategic integration of operational assessment into the regeneration of urban wastelands in sustainable neighborhoods, in N. Marchettini, C. A. Brebbia, R. Pulselli and S. Bastianoni (eds.) The Sustainable City IX. Urban Regeneration and Sustainability, Vol. 1, WIT Transactions on Ecology and the Environment, Vol. 191, Wessex Institute of Technology, WIT Press, Southampton \& Boston, pp. 65-73.

[3] Barelkowski, R.: 2014, Strategies for identity of sustainable suburbs, in N. Marchettini, C. A. Brebbia, R. Pulselli and S. Bastianoni (eds.) The Sustainable City IX. Urban Regeneration and Sustainability, Vol. 1, WIT Transactions on Ecology and the Environment, Vol. 191, Wessex Institute of Technology, WIT Press, Southampton \& Boston, pp. 667-679. 
[4] Crainic, T. G., Ricciardi, N. and Storchi, G.: 2009, Models for Evaluating and Planning City Logistics Systems, Centre Interuniversitaire de Recherche sur les Reseaux d'Entreprise, la Logistique et le Transport CIRRELT, Montreal.

[5] Seasons, M.: 2002, Evaluation and municipal urban planning: Practice and prospects, The Canadian Journal of Program Evaluation, 17(1), pp. 43-71.

[6] Kay, J. J., Regierb, H. A., Boylec, M. and Francis, G.: 1999, An ecosystem approach for sustainability: addressing the challenge of complexity, Futures, 31(7), pp. 721-742.

[7] Kay, J. J.: 2000, Ecosystem as self-organizing Holarchic Open Systems: Narratives and the Second Law of Thermodynamics, in S. E. Jorgensen and F. Mueller (eds.), Handbook of Ecosystem Theories and Management, CRC Press - Lewis Publishers, pp. 135-160.

[8] dos Santos, C. B.: 2003, A Socioecological Approach to Territorial Systems in Mediterranean Environments, Discussion Papers - Spatial and Organizational Dynamics, No 9, pp. 7-33, retrieved on $1^{\text {st }}$ June 2015, http://www.cieo.pt/discussionpapers/9/article1.pdf

[9] Janusz, J., and Wardeski, L.: 2014, FAST: instant verification of the results of planning decisions, in N. Marchettini, C. A. Brebbia, R. Pulselli and S. Bastianoni (eds.) The Sustainable City IX. Urban Regeneration and Sustainability, Vol. 1, WIT Transactions on Ecology and the Environment, Vol. 191, Wessex Institute of Technology, WIT Press, Southampton \& Boston, pp. 691-700.

[10] CEC: 1994, CORINE Land Cover - Technical guide, retrieved on $1^{\text {st }}$ June 2015, http://reports.eea.europa.eu/COR0-landcover/en

[11] EEA: 2006, The thematic accuracy of CORINE Land Cover 2000. Assessment using LUCAS (land use/cover area frame statistical survey), Technical Report 7/2006, retrieved on 15 ${ }^{\text {th }}$ May 2015, http://reports.eea.europa.eu/technical_report_2006_7/en/technical_report_ 2006_7.pdf

[12] Barelkowska, K. and Chlasta, L.: 2014, Suburban buffers as key areas in a sustainable city, in N. Marchettini, C. A. Brebbia, R. Pulselli and S. Bastianoni (eds.) The Sustainable City IX. Urban Regeneration and Sustainability, Vol. 1, WIT Transactions on Ecology and the Environment, Vol. 191, Wessex Institute of Technology, WIT Press, Southampton \& Boston, pp. 681-690.

[13] Barelkowski, R.: 2016, Planning for sustainable development of energy infrastructure: FAST - Fast Simulation Tool, International Journal of Energy Production and Management, Vol. 1, No. 1, Wessex Institute of Technology, WIT Press, Southampton \& Boston, pp. 61-71.

[14] Dawson, R., Wyckmans, A., Heidrich, O., Koehler, J., Dobson, S. and Feliu, E.: 2009, Understanding Cities: Advances in Integrated Assessment of Urban Sustainability, Centre Interuniversitaire de Recherche sur les Reseaux d'Entreprise, la Logistique et le Transport CIRRELT, Montreal. 